\title{
Comentario a Max Weber: "Prestigio del poder y sentimiento nacional” Comment on Max Weber: "Prestigio del poder y sentimiento nacional”
}

\author{
Joaquín Abellán García \\ Universidad Complutense de Madrid \\ joaquin.abellan@cps.ucm.es
}

\author{
Cita recomendada: \\ Abellán García, J. (2019). Comentario a Marx Weber: "Prestigio del poder y sentimiento nacional”. Eunomía. \\ Revista en Cultura de la Legalidad, 17, 349-353. \\ doi: https://doi.org/10.20318/eunomia.2019.5038
}

Recibido / received: 29/08/2019 Aceptado / accepted: 02/09/2019

El comentario a este texto quiere plantear solamente la pregunta de por qué "nación" no es un concepto sociológico fundamental en la obra de Max Weber. No abordo aquí la posición valorativa de Weber respecto a la nación -el valor más elevado para élni las valoraciones que se han hecho entre los investigadores sobre esta posición de Weber ${ }^{1}$.

El texto, del que procede este pasaje, así como otros dos textos escritos entre 1910 y 1912 y contenidos asimismo en Economía y Sociedad ${ }^{2}$, muestran que Max Weber no elaboró sobre la "nación" un tipo ideal, es decir, un concepto teórico con capacidad analítica. Max Weber pasa a revista a los múltiples significados que se le atribuyen a la "nación" y no llega a darle al concepto "nación" un estatus teórico dentro de su sociología comprensiva.

Resumiendo, en la variedad de significados contenidos en el fragmento seleccionado se puede observar que Weber busca un significado para "nación" por la vía de la exclusión. El primer significado de uso más común es el que denomina como "nación" a un grupo humano en el que "cabe esperar que haya un sentido específico de solidaridad entre los componentes de ese grupo», y Weber señala su carácter

\footnotetext{
${ }^{1}$ Las valoraciones sobre la posición de Max Weber sobre la nación y el nacionalismo han sido muy distintas y contrapuestas. Véánse especialmente Wolfgang J. Mommsen (1974), Wilhelm Hennis (1996), Kari Palonen (2001) y Uta Gebhard (2004).

2 Se trata de "Ethnische Gemeinschaften" [Comunidades étnicas] y "Politische Gemeinschaften" [Comunidades políticas], en: Max Weber Gesamtausgabe, pp. 168-190 y 204-215, respectivamente.
} 
indeterminado. También menciona otro significado de nación como «pueblo de un Estado», pero señala Weber que una nación no coincide con «el pueblo de un Estado», pues hay comunidades políticas o Estados que incluyen algunos grupos de ciudadanos que se presentan a sí mismos como naciones. Acerca de la definición de la nación como una "comunidad lingüística" también indica Weber que hay ejemplos de comunidades en las que compartir el mismo idioma no es suficiente para ser nación, pues hay otros factores, como la religión u otros factores sociales, que dividen fuertemente a los miembros de esa comunidad de lengua. Respecto a esa identificación entre comunidad lingüística y nación, Weber menciona varios ejemplos de comunidades con una lengua común que no se perciben como nación y de comunidades en las que sí existe una pretensión de serlo en alguno de sus grupos integrantes; o también alude al caso de comunidades con un idioma común, que comparten ese idioma con los habitantes de otro Estado y que se sienten y declaran, sin embargo, miembros de otra comunidad política; incluso, pone un ejemplo de cómo en alguna comunidad lingüística las respuestas de sus miembros a si se consideran una nación son muy distintas según el lugar de la diáspora en que vivan. En la referencia al "sentimiento nacional" en el propio fragmento seleccionado, Weber llega a la misma conclusión, pues el sentimiento nacional del alemán, del inglés, del español, etc. no funciona de la misma manera.

Con esta situación tan variada de casos y ejemplos que Weber expone en el texto (la afirmación enfática por parte de una comunidad de percibirse como nación, el rechazo a considerarse una nación, o la indiferencia hacia la idea de nación), él considera que el concepto "nación" está denominando realidades tan diversas y dispares que no es posible construir un concepto de "nación" que pueda cumplir las funciones que cumplen los conceptos en la ciencia social que él está estableciendo. El mismo afirma que no se puede intentar hacer una "casuística sociológica" en relación con el concepto valorativo "nación", que es totalmente polisémico desde un punto de vista empírico, pues tendría que desarrollar todas las clases de sentimiento de comunidad, sus orígenes y las consecuencias que tienen para la acción de los miembros de esas comunidades. Es decir, el concepto "nación" o "sentimiento nacional" no permite ser utilizado para indicar las causas o motivos de una acción social o sus consecuencias, que es la función principal de los conceptos en su "sociología comprensiva". La pregunta que hace en el texto en relación con el "sentimiento nacional" o con la "nación", y que no puede ser respondida con los distintos significados de nación mencionados, es precisamente ésta: "¿qué consecuencias está dispuesto un grupo de personas a extraer del "sentimiento nacional" para el desarrollo de una acción social concreta?». En la misma línea va la afirmación de Weber, en los primeros párrafos del textos seleccionado, cuando, después de referirse al sentido usual de "nación" como poder esperar una solidaridad mutua y recíproca entre los miembros de un grupo humano, añade que con esa definición no se puede saber ni cómo se organizarán esos grupos ni qué tipos de acción se van a derivar de esa solidaridad, es decir, no se puede obtener aquello que se espera precisamente con la construcción de un tipo ideal.

Por esta vía de la exclusión sabemos que, para Weber, la nación no es una "comunidad étnica": la etnia no es un criterio claro, firme, sobre el que hablar de nación, pues no se puede establecer con él qué tipo de acción comunitaria se deriva sobre la base del parentesco ${ }^{3}$. También sabemos que excluye todos los factores de

\footnotetext{
${ }^{3}$ En el segundo congreso de Sociología, celebrado en Berlín en 1912, al comentar Weber la ponencia de Paul Barth sobre "Die Nationalität in ihrer soziologischen Bedeutung" [La nacionalidad en su significación sociológica], dice sobre la validez del criterio racial para el análisis que un yanqui acepta como compatriota a alguien que tenga un cuarto o un octavo de indio, pero no acepta a un negro, aun cuando adoptara las mismas pautas de comportamiento y tuviera las mismas aspiraciones sociales. Esta repulsión era puramente de carácter social, no racial (Weber, 1988, p. 485).
} 
tipo cultural, como la religión, el idioma, las costumbres, incluso aunque de éstas surgiera una comunidad con un tipo antropológico específico. $Y$ sabemos que tampoco es un criterio para la definición la pertenencia a un Estado, pues como ya se ha dicho antes la nación no es intercambiable con "pueblo del Estado", aunque el Estado sí puede hacer posible una nación. Después de este proceso de exclusión, cabe decir que Weber sólo encuentra un único elemento que permitiría definir la nación y éste es su orientación hacia el Estado. En el texto "Etnische Gemeinschaften" escribe:

Una y otra vez encontramos en el concepto "nación" una relación con el "poder" político; lo "nacional" -si es que eso es realmente algo unívoco- es un tipo específico de pathos que, en un grupo de personas unidas por una común lengua, o confesión, o destino, o costumbres comunes, va asociado a la idea de una forma de organización del poder político propio, sea ésta ya existente o añorada, y cuanto más énfasis se pone en el "poder", más específico es [el pathos]. Este orgullo sentido por el poder poseído o por la añoranza del "poder" político abstracto de la comunidad puede estar, como tal, más extendido en una comunidad cuantitativamente "pequeña" -como la comunidad lingüística de los húngaros, de los checos o de los griegos de hoy- que en otra comunidad cualitativamente similar, pero cuantitativamente mucho más grande, como, por ejemplo, los alemanes de hace un siglo y medio, que en esa época eran esencialmente una comunidad lingüística, pero que no tenía ninguna pretensión de un poder "nacional" (Weber, 2001a, p. 190).

Según esto, para Max Weber una comunidad sólo forma una nación cuando actúe como una organización de poder político, lo que en los tiempos modernos significa estar organizada como Estado.

Esta definición, que parece clara, no deja de ser una definición abierta, pues como observa Dieter Langewiesche $(2016)^{4}$, tanto la nación como el Estado no tienen un tratamiento sistemático en Max Weber. Y la nación está todavía menos tratada sistemáticamente, sin que llegara a ser una categoría teórica en su sociología. La razón principal por la que Max Weber no elevó el concepto de nación a una categoría sociológica básica está en que ese concepto se volatiliza cuando se quiere hacer de él un tipo ideal, es decir, un concepto compacto, con coherencia interna entre sus ingredientes. La categoría "nación" resulta demasiado indeterminada, indefinida, para el análisis de las causas de las acciones de los individuos, pues los elementos que están asociados a nación empíricamente, en la historia, son heterogéneos, dispersos, no próximos. Como ya hemos mencionado anteriormente, el significado de "nación" no nos dice nada sobre el origen o las causas de la comunidad, pues sólo nos dice una cosa respecto a su objetivo o meta: el poder político, el tener un Estado propio. El concepto de nación, con sólo esta referencia al Estado, no nos puede decir nada más sobre quién actúa, con qué intereses actúa. Es decir, un concepto de nación así no serviría para su función de analizar y explicar la acción de los individuos, de una comunidad. Un concepto así no sirve para el análisis empírico ${ }^{5}$.

\footnotetext{
${ }^{4}$ Véase, Dieter Langewiesche (2016, pp. 39-65).

${ }^{5}$ Recuérdese, por ejemplo, que en la sociología del poder, Max Weber no utiliza el concepto de "Macht" entre sus conceptos fundamentales, porque lo considera amorfo, indeterminado, desde el punto de vista sociológico. "Macht", con un significado tan indeterminado que puede abarcar cualquier forma de imposición de la voluntad de una persona sobre la de otra (incluso en contra de la voluntad de esta otra persona sobre la que se ejerce) y que puede ejercerse por cualquier motivo posible y sin ningún tipo de regularidad, es por ello un concepto "amorfo" con el que no se puede emprender ninguna tipificación conceptual de modo que tenga capacidad analítica a la hora de imputarle causas o motivos a una acción social o de poder derivar de ella consecuencias. A diferencia de "Macht", con el concepto "Herrschaft" Weber denomina a una relación de poder clara entre alguien que manda y alguien que acepta obedecer porque tiene un motivo para ello (considerar legítimo al que le manda). Dicho sea de paso: nuestro término "dominación" para traducir "Herrschaft" no contiene directamente esas características de la
} 
Langewiesche señala además otra razón. Como es sabido, desde 1910 aproximadamente, Max Weber ensanchó su perspectiva de análisis para incluir una perspectiva de historia universal. Y en esta perspectiva el concepto de nación tampoco ocupa un lugar. Si la nación está orientada hacia el poder (Estado), en un Estado-nación, o Estado nacional, ¿qué aporta la nación? ¿Qué añade "nacional" a Estado? Estado y nación se funden mutuamente y son un Estado. La denominación "Estado nacional", por cierto, apenas la utiliza Max Weber. ¿Qué le añade lo nacional al Estado desde la perspectiva de la historia universal? Algunos autores habían querido ver en lo "nacional", en el Estado nacional, que lo nacional podría añadir algo, en el sentido de darle al Estado una base más amplia de participación y de legitimidad, es decir, que la nacionalización del Estado podría tener un efecto democratizador, de una mayor participación ${ }^{6}$. Pero Weber entendía al Estado como una relación de poder-obediencia muy precisa, y contaba con todos los elementos para su papel. Otros elementos, como a los que aludía Robert Michels, no entran el concepto de Estado. El Estado sí cabe en una perspectiva de historia universal, mientras que la nación, según Weber, no suministraba conceptos viables para ello (Langewiesche, 2016, pp. 48-49).

En los años de la Primera Guerra Mundial, sin embargo, Max Weber experimentó que la "nación" estaba por encima del Estado. La definición de la nación incluía esa orientación de la nación hacia el poder político, hacia el Estado, y el Estado era para Weber la más alta organización del poder en la tierra. Pero durante la guerra se puso de manifiesto que el Estado necesitaba la aprobación de los hombres, algo que se podía conseguir a través del "sentimiento nacional". Este sentimiento era imprescindible para la comunicación entre los militares y los soldados, para la lucha como tal, para soportar y explicar la experiencia de la derrota. El Estado entonces estaba necesitado existencialmente de esa "confesión" nacional. Pero el Estado que puede mucho, no lo puede todo, y no puede obligar a los demás a "una entrega libre" al Estado. A la nación (comunidad cultural), sin embargo, sí se le da esa entrega libre y voluntariamente.

En esta situación, Weber pudo observar y reconocer que lo nacional tenía efectos sobre las acciones de los individuos en el frente, que el sentimiento nacional -que en las páginas anteriores hemos visto como indeterminado, no preciso, a la hora de construir un concepto teórico- podía establecer comportamientos, y no sólo para los presentes, sino también para los descendientes, es decir, la nación podría obtener un estatus teórico distinto, pero Max Weber no lo hizo. La nación había sido el valor más alto para él y ahora, al final de la guerra, también lo era como punto de referencia para la construcción del futuro de Alemania. Pero Weber no llevó al concepto lo que la realidad estaba mostrando, y no categorizó teóricamente el concepto de nación. Como ya anuncia Langewiesche en el título de su trabajo, el sociólogo Weber enmudece ante su máximo valor (la nación).

\footnotetext{
definición weberiana de "Herrschaft". Por ello, no resulta adecuado para traducirlo y se hace necesaria una explicación complementaria para no desviarse del concepto weberiano.

${ }^{6}$ Robert Michels, por ejemplo, en el Segundo Congreso de Sociología en Berlin, 1912. Véase Weber et al (1913).
} 
Bibliografía

Gebhard, U. (2004). The meaning of Honour in Weber's Concept of Nation. Max Weber Studies, 4(2), pp. 221-233.

Hennis, W. (1996). Max Webers Wisenschaft vom Menschen. Neue Studien zur Biographie des Werks. Tübingen: Mohr Siebeck.

Langewiesche, D. (2016). Nation bei Max Weber: soziologische Kategorie und politische Bekenntnis. Zum Verstummen des Soziologen als homo politicus vor seinem Wertgott. En D. Lehnert (ed.), Max Weber 1864-1920. Politik - Theorie Weggefährten. Köln, Weimar, Wien: Böhlau Verlag, pp. 39-65.

Mommsen, W. J. (1974). Max Weber und die deutsche Politik 1890-1920, $2^{\mathrm{a}}$ ed., Tübingen: Mohr Siebeck.

Palonen, K. (2001). Was Max Weber a Nationalist?? A Study in the Rhetoric of Conceptual Change. Max Weber-Studies, 1(2), pp. 196-213.

Weber, A., Barth, P., Schmid, F., Moritz Hartmann, L., Oppenheimer, F., Michels, R. (1913). Verhandlungen des Zweiten Deutschen Soziologentages vom 20. Bis 22. Oktober in Berlin. Reden und Vorträge von Alfred Weber, Paul Barth, Ferdinand Schmid, Ludo Moritz Hartmann, Frans Oppenheimer, Robert Michels und Debatten. Tübingen: Sauer u. Auvermann.

Weber, M. (1988), Gesammelte Schriften zur Soziologie und Sozialpolitik. $2^{\circ}$ ed. (edición de Marianne Weber). Tübingen: J.C.B. Mohr.

Weber, M. (2001a). Ethnische Gemeinschaften. En Max Weber Gesemtausgabe Wirtschaft und Gesellschaft. Die Wirtschaft und die gesellschaftlichen Ordnungen und Mächte. Nahlass. Teilband I: Gemeinschaften. Edición de Wolfgang J. Mommsen. Tübingen: Mohr, pp. 168-190.

Weber, M. (2001b). Politische Gemeinschaften. En Max Weber Gesemtausgabe Wirtschaft und Gesellschaft. Die Wirtschaft und die gesellschaftlichen Ordnungen und Mächte. Nahlass. Teilband I: Gemeinschaften. Edición de Wolfgang J. Mommsen. Tübingen: Mohr, pp. 204-215.

Weber, M. (2001c). Machtprestige und Nationalprestige. En Max Weber Gesemtausgabe Wirtschaft und Gesellschaft. Die Wirtschaft und die gesellschaftlichen Ordnungen und Mächte. Nahlass. Teilband I: Gemeinschaften. Edición de Wolfgang J. Mommsen. Tübingen: Mohr, pp. 240-247. 